\title{
Self-employment and field of education understood from current entrepreneurship research
}

\author{
Caroline Berggren \\ Department of Education and Special Education, \\ University of Gothenburg, Gothenburg, Sweden, and \\ Anders Olofsson \\ Department of Education, Mid Sweden University, Härnösand, Sweden
}

\begin{abstract}
Purpose - The purpose of this paper is to look at how results from a large-scale study can be understood in the context of contemporary gender and entrepreneurship research.

Design/methodology/approach - This study is inspired by a mixed methods methodology. To gain a qualitative understanding of the general patterns in a large-scale study, research results in articles from the International Journal of Gender and Entrepreneurship (IJGE) were used. To make such a heterogeneous research field as appears in IJGE comparable, a model was created that helped us to focus our attention when reading the articles. The core of each article was identified.

Findings - The categorisation of the articles in IJGE resulted in three perspectives: liberal, functional and structural. The liberal and functional perspectives improved our understanding only partially because these perspectives usually focused on a certain aspect in the society. The structural perspective more readily lent itself for interpretation of our large-scale results.

Research limitations/implications - The dissonance between our perspective and the perspective of others has been a challenge; it has been a delicate task.

Originality/value - This could be a way to improve communication of research not only within a perspective, but also between perspectives. It is important that scholarly journals provide the possibility to express different perspectives on, as in this example, gender and entrepreneurship.
\end{abstract}

Keywords Higher education, Gender, Entrepreneurship, Self-employment, Mixed methods

Paper type Research paper

\section{Perspectives on gender and entrepreneurship research}

Articles reporting research on women and entrepreneurship began to appear since the late 1980s. Gender-conscious researchers within the entrepreneurship and business fields described the characteristics of well-educated women's self-employment. Concerning Sweden, Holmquist and Sundin (1990) published a study that showed that highly educated, self-employed women had often finished studying before graduation, or that they had quit working to become self-employed. Self-employed women were

Our thanks go to the two anonymous reviewers who have invested a great deal of effort into improving our manuscript. The study was made possible by financial support from the Swedish Research Council and EU goal 2.
Received 29 March 2013

Revised 18 October 2013 Accepted 9 December 2013 
$\underset{7,3}{\text { IJGE }}$

292

divided into two groups: first, women with career aspirations to develop their business, and second, women who had families and who found self-employment to be a way to combine family responsibilities and paid work. Holmquist and Sundin (1990) stressed that highly educated self-employed people are few in number overall, and that women are relatively rare among the self-employed.

Research on entrepreneurship has expanded rapidly during the past three decades, and several journals with a focus on entrepreneurship have been established and more are being launched. After Schumpeter's (Schumpeter and Schumpeter, 1994) pioneering work on entrepreneurship and innovation, research about the origins of innovation and how businesses are run has mainly been studied within schools of business in industrialised countries. According to From (2010), entrepreneurship research within social science is such that entrepreneurship is situated in certain types of region (e.g. the city and the countryside); that it is contextualised in relation to surrounding influencing factors (e.g. different conditions for regional development); that it has an individual focus, for example, individual activities supporting entrepreneurship based on certain sets of personal behaviours, qualities and values; and, more recently, that entrepreneurship is about individuals who address social needs as their business ideas (e.g. improvement of social services). Moreover, the concept of entrepreneurship has been discussed (Bjerke, 2013) and seems to include being an entrepreneur according to Schumpeter's definition and being self-employed in the sense of running a business. In this article, we use entrepreneurship and self-employment as interchangeable concepts.

Entrepreneurship research from a global perspective has become more common during the past decade. However, the gender perspective does not belong to the mainstream, and does not appear in discussions about the impact of Western and androcentric values on this field of research.

\section{Point of departure}

A study based on data from Swedish registers showed the labour market situation for tertiary-educated people in 2006. Our understanding of gender is that it is "done" or constructed, and this doing is performed on several levels in society. The doing is about separating people into two groups: women and men; as a consequence, a hierarchization will take place where men are considered the most status worthy (Acker, 1990; Bourdieu, 2001; Ridgeway, 1997; West and Zimmerman, 1987). Concerning the transfer of family resources from one generation to another, we rely mainly on Bourdieu (Bourdieu and Passeron, 1990). Our results showed that men were two and a half times more likely to have a business as compared with women, irrespectively of field of study. The analysis was based on a representative group of 88,319 ex-higher education students in their early 30s. The size of the population made it possible to control for several influencing factors: field of study, type of higher education institution, previous unemployment, completed or incomplete higher education programme, level of previous educational achievement and parents' educational level and parents' self-employment. Even when these factors were the same, men were more likely to become self-employed. Among tertiary-educated people overall, being solely self-employed was relatively unusual: 2 per cent of men and 1 per cent of women were self-employed. A somewhat larger proportion appeared in combined employment and self-employment: 11 per cent of men and 5 per cent of women. Those educated within the fields of agriculture and forestry and fine arts were the most likely to be self-employed, predominantly men within 
agriculture and forestry, and women within fine arts. The assumption that those educated in business, natural sciences and technology are more likely to become self-employed probably arises from the fact that large numbers of students are educated in these fields, which makes them visible in the society. (For more information about these results, see Berggren and Olofsson, 2011).

\section{Choice of methodology}

The large-scale study provides valid and reliable information on the prevalence of self-employment among different groups of tertiary-educated people. It is possible to rule out several individual explanations for women's lower self-employment, such as not being educated within the "right field", having graduated from a less prestigious higher education institution or not having self-employed parents as role models. The patterns that women are less likely to become self-employed than men are evident and similar to the patterns in many other countries; however, the large-scale study cannot offer a qualified understanding for these patterns. Therefore, we turned to the International Journal of Gender and Entrepreneurship (IJGE) which receives contributions from all over the world, written from a range of perspectives and methodologies, but with the uniting focus on women's conditions and their possibility to become self-employed. We expected to find a wide range of experiences reported in the papers published in this journal, and among them explanations for the patterns that we had observed in our own study concerning the prevalence of self-employment among women and men.

Greene $(2007,2012)$ advocates using and integrating empirical results from a wider than usual range of different data sources or discourses, that is, beyond traditional triangulation. Greene (2012, p. 758) calls her approach "mixed method heavy", which:

[...] involves mixing at all three levels of method, methodology, and paradigm/mental model. These studies require advance legitimization and acceptance of the multiple ways of knowing being included in the study and further, in my way of thinking, purposefully invite respectful dialogues among them. These studies thus have the generative potential for meaningful insights - sometimes through dissonance - that can dialectically catalyse new and deep understandings not possible with one methodological standpoint alone.

A democratic and respectful exchange of ideas is stressed by Greene, and as we see it, this is somewhat different from the academic tradition where the advocacy of a certain standpoint is common.

To be able to make such a heterogeneous research field as appears in IJGE comparable, a model that can encompass the variation of all the articles in the journal is needed. We chose a model that makes it possible to compare our results with any methodological point of departure, irrespective of the content the articles.

To create this model, we combined two theoretical sources for our analysis: Ahl (2006) and Holmquist (2002). The choice of Ahl (2006) is based on her international reputation, particularly her discourse analysis of women's entrepreneurship. Ahl (2006) called for an expanded analysis on women's entrepreneurship; she analysed the variation in discursive practices of women's entrepreneurship expressed in 81 articles published in international journals, the majority of them in four leading journals. She summarised gender research into three all-embracing categories: liberal feminist theory, social feminist theory and social constructionist/post-structural feminist theory. First, liberal feminist theory perceives women and men as being equal and equally as able to run businesses. Men make up the uncontested norm to which women should adapt. 
$\underset{7,3}{\text { IJGE }}$

294

Second, social feminist theory perceives women and men as being different; their contributions to society are equally valued, but are different. The way men run businesses is uncontested; whereas, women's ways of running businesses are seen as complementary. Third, social constructionist/post-structural feminist theory perceives gender as a social construction that varies depending on time and context. This type of research challenges seemingly natural gender behaviour and examines how gender is created.

Within these three categories, Ahl (2006) constructed discursive practices in her analysis of the journal articles; that is, she analysed theoretical points of departure and the ontological and epistemological premises that are implicitly or explicitly stated. These premises influence researchers' choice of questions, theory and research method. The result of her analysis was a description of ten discursive practices, all of which contributed in different ways to reproduce women's subordination to men. To avoid the production and reproduction of women's subordination in society, Ahl (2006) suggested an expansion of the research object from a focus on the individual to more complex studies, including more influencing factors to reveal the mechanisms that produce and reproduce gender, a shift from an objectivist to a constructionist research approach.

In contrast to Ahl, Holmquist has published predominantly in Swedish. It was particularly Holmquist's (2002) ambition to combine gender theory and mainstream entrepreneurship theory, despite their different epistemologies, and that is what caught our attention. The foci in gender theories are the structures: the gender system in which women and men are treated as separate and men make up the norm. Entrepreneurship theory focuses on the individual, the creator, based on an unquestioned white, middle-class, male model that neglects existing power relationships. In society, both men and women are self-employed, but women are more likely to remain invisible to entrepreneurship researchers who have not had training in gender theory. To describe and compare the two research traditions, Holmquist raised four topics: first, the range of the theory, what it is about; second, the purpose of the theory, for example, how to discover the true entrepreneur or how to understand entrepreneurship as a phenomenon; third, level and object, for example, the individual or the society; and fourth, the methodology, for example, questionnaires or ethnography.

To summarise, we had three analytical categories and four key issues that helped us to focus our attention when reading the articles.

Another possibility to compare articles could have been to use a single theory as a tool. An example could be to apply a structural theory about men as the uncontested model (Bourdieu, 2001; Ridgeway and Correll, 2004). We would then have directed our attention to the male norms that different articles express, or do not express. We argue that this alternative would be too restrictive, taking only one dimension into account that is the dimension of power. Instead, our suggested model opens up for the possibility to take advantage of more of the information that is available in the articles.

\section{Method}

In this paper, research articles published in the IJGE were chosen for analysis of theory, purpose, object and methodology. All 58 research articles published from 2009 to 2012 were analysed. This excluded calls for papers, conference reports, book reviews, practitioner papers and similar contributions. The reason for choosing this particular 
journal was that it specialises in gender and entrepreneurship, and it is international in more than the name, with contributions from all over the world.

We analysed the theories that were applied as to whether they examined the individual, the self-employed, the organisation of the labour market, the gender system, or others, and we categorised them into the three large groups introduced by Ahl (2006). Holmquists' four key issues helped us focus our attention and not to become distracted by other interesting information. Concerning the purpose of the articles, we determined whether they were descriptive or normative. The objects that appeared in the articles have been categorised into three groups: individual, context or society. When the focus was on how the studies were carried out, the method had been chosen in relationship to the object; that is, when few women were studied, they were likely to be interviewed, while if there were many subjects, they have had been asked to answer a questionnaire and so on. Connected with this, we also noted that several of the studies were based on convenience sampling. Not all key issues were expressed in all articles. In most of the empirically based articles, the starting point was a question without an explicit theory of gender differences. The range of theories was instead determined by the empirical question in relation to the study object as expressed by the author(s).

The analysis was done in three steps. First, Ahl's three all-embracing categories (Table I) were used as a tool to describe the articles in IJGE. Second, by adding information from the IJGE articles about the theoretical variation, purpose and method to Ahl's three categories, the categories became richer. Finally, the rewritten categories were used as lenses to reinterpret the results from our large-scale study. Our aim was to find a core in the articles that expressed the authors' understanding and expression of women's options for becoming self-employed. This "core" was relatively stable through the articles in IJGE, and it was possible to categorise all articles into one of the three categories we developed during the analysis. However, there were several examples among the articles in which authors expressed more than one perspective on how to understand the prerequisites and the situation for self-employed women; deviations from the dominant perspective were particularly evident in the discussions and in the implications.

The categorisation of the articles was first done independently by both of us and, thereafter, the results were compared. Our categorisation corresponded with respect to 54 of the 58 articles. Moreover, a colleague within education and entrepreneurship read a sample of 10 of the articles and sorted them into the same categories as we had done. This was a way to validate how well the categories communicate and the reasonableness of the categories.

The registers, we analysed in our large-scale study, came from Statistics Sweden.

Statistics Sweden only records whether a person obtains an income as an employed or as a self-employed person. We did not have the possibility of differentiating between the innovative aspect of entrepreneurship and the aspect of earning a living. Therefore,

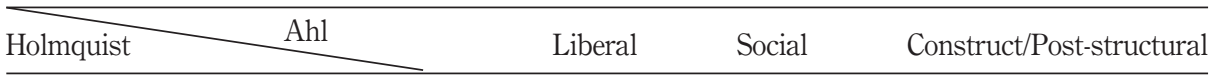

Range of theory, what is it about

Purpose of theory, how to understand

Level of object, individual - > society

Methodology, choice of method

Table I.

Model for categorisation of scholarly articles in 
IJGE

7,3

296

we did not differentiate the articles in IJGE according to self-employment or entrepreneurship/innovation.

\section{Results}

Ahls' original categories were rewritten into liberal, functional and structural perspectives. The liberal was the most common perspective, seen in 31 out of the 58 papers. Structural perspectives were found to be dominant in 18 of the 58 and the functional perspective in 9 of the 58 articles (Table II).

It is possible to see the influence of guest editors of special issues. For example, Helene Ahl and Teresa Nelson were guest editors of issue January 2, 2010, which radically increased the influence of the structural perspective. The editors have written within this perspective themselves, and we believe that they are likely to attract similar perspectives.

This bar graph shows Holmquist's key issues on the x-axis: purpose, object and method is shown, while the categories show the range of theory.

\section{Liberal perspective}

Within this category, the authors assume that women and men are similar and that their prerequisites for becoming an entrepreneur are similar. The assumptions are based on the liberal and neoliberal idea that the individual has the freedom to choose, and on a belief that the free market, governed by supply and demand, is self-regulating. This perspective is based on androcentric ideals with the white, middle-class man making up the norm and is not subjected to reflection. This liberal perspective considers the hurdles that women experience as self-employed individuals and suggest changes (e.g. education and co-operation) that will make self-employed women become more successful. If women accomplish these changes, they will become as successful as men. An unawareness of the different societal conditions for men and women was salient, and men's perspectives on entrepreneurship were accepted. Slightly more than half of the articles had a normative research approach ( $n=17$, see Figure 1$)$, and entrepreneurship

\begin{tabular}{lccc}
\hline Volume/issue year & Liberal & Functional & Structural \\
\hline $4 / 32012$ & 2 & 2 & 1 \\
$4 / 22012$ & 4 & 1 & \\
$4 / 12012$ & 3 & 1 & 1 \\
$3 / 32011$ & 4 & 1 & 1 \\
$3 / 22011$ & 3 & 1 & 1 \\
$3 / 12011$ & 3 & 1 & 1 \\
$2 / 32010$ & 2 & & 1 \\
$2 / 22010$ & 2 & & 2 \\
$2 / 12010$ & 1 & 1 & 5 \\
$1 / 32009$ & 3 & 1 & 1 \\
$1 / 22009$ & 2 & 9 & 3 \\
$1 / 12009$ & 2 & & 18 \\
Total & 31 & &
\end{tabular}

Categorisation of scholarly articles in IJGE
Note: The inter-subjective correlation between the authors distribution of categories of the articles was 0.93 
was seen as neutral and good. Empirically, there were variations regarding sampling and methodology. Surveys were the most common, followed by interviews. Regarding the reliability, less than one-third of the samples were randomly drawn from the population. Finally, theories were seldom explicit in the articles classified as liberal.

An example of the liberal perspective is gender and the small and medium-sized enterprise (SME) "finance gap" by Watson et al. (2009, Vol. 1 No. 1, pp. 42-56). The authors studied gender differences in the use of funding. They described the differences between men and women's self-employment, and found that women and men were running businesses in different sectors of the labour market. They also showed that women had more formal education than men did, and that women were older than men were when they started their businesses. A questionnaire measuring the attitudes of male and female small business owners towards external funding was distributed, and the answers were compared. Results showed that accessibility to funding was equal for men and women and that men and women run businesses of equal size and turnover. However, they were active in different types of markets.

The fact that women and men were active within different sectors of the labour market was not commented upon or discussed. Instead, the authors stressed that women and men had equal access to funding, that they were equally successful, and that running a business was beneficial for both men and women.

\section{Functional perspective}

This category perceives a fundamental difference between men and women, but the difference is not seen as a problem. It is normatively presupposed that the differences can be functional under certain conditions. Women and men can be entrepreneurial to the same extent, but women need to be supported. The reason for this need of support is that institutions do not acknowledge that women tend to run different kinds of businesses differently from men. There is a need for greater acceptance of women running businesses to develop and benefit from them and their particular contributions to the society.

The theoretical perspective in these articles was the fundamental difference between men and women. Moreover, women were perceived as hampered and unable to develop their special qualities. Within this perspective, studies were often contextualised and mixed methods or interviews were applied. In the majority of the articles, the empirical focus was on women. There seemed to be limited awareness of sampling.

An example of this perspective is "The politics of gendered growth" by Fleck $e t$ al. (2011, Vol. 3 No. 2, pp. 164-173). In this study, 33 female Irish entrepreneurs were

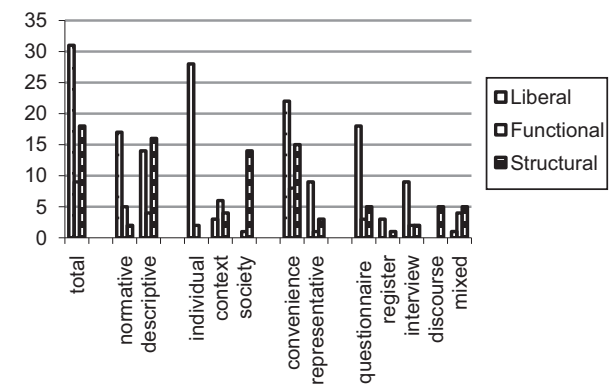

Figure 1.

Number of articles within each category,

purpose, level of object, type of sample and method 
$\underset{7,3}{\text { IJGE }}$

298

interviewed. The results showed the barriers faced by these women when running their businesses. The women's answers related to available support programmes. The authors argued that the support programmes needed to be adjusted to women's particular situations. Moreover, they suggested what women could do to improve their skills and confidence and to relieve them of their parental obligations.

\section{Structural perspective}

Social mechanisms that produce and reproduce different conditions for women and men were at the core of this perspective. Ascertaining whether gender or sex differences exist and how they appear was not the issue; the focus was on how socialisation and upbringing vary over time and between different societies and how this situation creates two types of human behaviour. Studies about differences between self-employed women and men aim to uncover the social structures that lead to maintained male dominance within entrepreneurship. The purpose was not to identify support strategies for self-employed women so they could become successful within a market defined by traditional male norms; instead, the purpose was to illuminate gender discrimination and to show that what is commonly perceived as objective and neutral is in fact based on traditional male norms, values and behaviours. Critical research along this line can form the basis for discussions about current policies and regulations, ensure that gender loses its relevance, initiate discussions about the development of new forms of coexistence and encourage new economic and societal organisations to appear. Examples include discussions about the taken-for-granted assumption that women should hold the main responsibility for family life, or critical analysis of regulations preventing the self-employed from combining their business activities with parental leave.

Research was carried out with several methods and theories. There were traditional empirical studies with use of representative samples, but theoretical argumentation in connection with mixed methods or discourse analyses were the most common. In contrast with articles written from the two other perspectives, almost all of those written from this perspective presented a descriptive purpose.

This category is exemplified by "Gender and entrepreneurial capital: implications for firm performance" by Shaw et al. (2009, Vol. 1 No. 1, pp. 25-41).

This article analysed the relationship between gender, entrepreneurial capital and firm performance. The aim was to understand how societal and cultural mechanisms contribute to the prevailing differences in business success between male and female entrepreneurs. Current policies do not acknowledge that women and men act in very different contexts, in both their professional and private lives. Policies do not question the male norm of performance, and therefore, women can never be perceived as successful. For example, self-employed women may prioritise personal development and independence rather than profit and growth, and the amount of business investment by women may be more dependent on private means as compared with their male counterparts. The authors argued that women's entrepreneurship should be seen in light of social structures that influence the perceptions, attitudes and behaviours of all members of society, including self-employed women. Knowledge about the relationship between gender and entrepreneurship in a wider perspective needs to be acknowledged and addressed to make policies successful in supporting self-employment among both women and men. 
Researchers within this perspective make use of a range of methods and theories. Traditional empirical studies had been conducted, but theoretical argumentation in connection with known facts or discourse analyses were mainstream.

\section{Using the three perspectives as an interpretative tool \\ Liberal perspective}

In large-scale studies, groups of individuals are analysed, and means and variance are used to describe groups and differences between groups. Within each group, there are individuals that apparently deviate from the mean. To a great extent, the liberal perspective is interested in these individuals. Innovative individuals can make up models and become forerunners in a development that will later be visible in large-scale studies.

Articles written from this perspective make up examples of Acker's (1990) theory of how gender is reproduced on a symbolic level. Ignorance of the fact that "neutral" policies and regulations are in effect androcentric (Bourdieu, 2001), act to preserve men's advantages. If the type of self-employment that men, to a large extent, try to attain corresponds to the "general" expectations of what entrepreneurship is, that will likely improve men's success rate. This perspective helps us to understand some of the unexplained differences in the prevalence of self-employment among women and men that was shown in our study.

An important and interesting result from our large-scale study was that the fields of fine arts, agriculture and forestry, and humanities and theology were more likely to lead to self-employment. One explanation is the structure of the labour market: the competition for employment in these fields is high, and, therefore, self-employment becomes an option. Within the liberal perspective, the results showing different likelihoods of self-employment in different fields can be understood as part of the whole market, in which individuals in some fields are successful, while individuals in other fields are not.

\section{Functional perspective}

This perspective considers men and women as essentially different. It contributes to an understanding of different processes for women and men during their upbringing and beyond. The gender different upbringing will lead to different educational choices and types of specialisations.

Our study shows that men were more than twice as likely as women to become self-employed, even within the healthcare sector, where women are in the majority. It is possible that women are active in running the businesses, but a man is more likely to be the person who is responsible for the whole organisation. The functional perspective could help us to describe how entrepreneurship is performed within the healthcare sector, or any other sector.

This perspective particularly supports women's needs and rights to expand the arena of what is considered to be entrepreneurship. However, this perspective does not contribute to an understanding of why our study showed that men were self-employed more often than women. This leads us to the viewpoint that power relationships between men and women have to be theoretically and empirically investigated as a relationship between men and women. In other words, differences can only be recognised and reflected upon if both sides of the coin are examined. 
IJGE

7,3

This perspective unfortunately restrains women by perceiving them in a complementary position, which leads to an unchallenged reproduction of the mainstream perception of entrepreneurship.

\section{Structural perspective}

This perspective lends itself more readily for interpretation of our large-scale results. It is useful for critical analysis of higher education and the subsequent labour market to improve understanding of patterns of how social class and gendered choices are reproduced. Such analysis and discussion will not focus on entrepreneurship as such, but on different aspects and mechanisms that contribute to gender differences in the society. The perspective allows an integration of discursive analysis with traditional large-scale studies of the relationship between higher education and women and men's entrepreneurship. For example, document analyses of various training programmes for the support of entrepreneurship among students in different fields of higher education can be examined and related to the actual differences we found in self-employment between women and men. Discussions would centre on how a gender-equal distribution of options could be developed and used to replace the mechanisms of power that now recreate the prevailing social order. Those power structures are obstacles for women becoming self-employed and for those with less entrepreneurial capital (Shaw et al., 2009). The structural perspective is open for analysis of different fields and how they relate to each other.

Within the structural perspective, it becomes possible to reveal the mechanisms behind prevailing entrepreneurship practice and to instigate a discussion about how and what entrepreneurship could be, if it is something different from the dominant definition. The structural perspective provides prerequisites and creates new possibilities in which dominant gender structures can be reconstructed to the advantage of new practices in which women and men can cooperate and engage in profitable businesses.

\section{Critical remarks and conclusions \\ Methodological critique}

The social structures that were primarily dealt with in the articles were gender, social class and ethnicity. We would like to see more articles that relate the choice of empirical data and methods to the context it is drawn from to show explicitly greater awareness of how social structures and the interaction between these structures influence different groups of people differently.

The majority of the articles in IJGE representing all three perspectives were based on small samples. It is not possible to draw any general conclusions from small samples in local contexts, unless the sampling method is done with great theoretical awareness. Convenience sampling was predominant; for example, women within certain networks were included and analysed, and the possible biased results that could be produced by such a sample were usually not discussed. Researchers did generalise results from small-scale studies to populations that were not part of the study.

Authors often wrote about relationships, for example, about female entrepreneurs in relation to male entrepreneurs. However, they did so without empirical analysis. It seemed as though the female entrepreneurs in some studies were related to the "image" of the entrepreneur. We are apprehensive because studies with such shortcomings 
contribute to a reproduction of male dominance within entrepreneurship research, as well as in a wider perspective.

The empirical base within the structural perspective was often built from discourse analyses of policies, articles or other documents. In these documents, expectations or thoughts about entrepreneurship and how it could be developed were expressed. However, from these studies it could not be ascertained whether the desired actions became reality. In our study, people's actual choices and actions were mapped out.

\section{A way forward - mixed method}

This has been an excursion into uncharted waters for us to try a democratic dialogue between epistemological and methodological perspectives other than our usual one. IJGE publishes contributions from a wide range of perspectives. The journal facilitates knowledge exchange between researchers and practitioners from different perspectives, but with the joint aim to broaden the understanding of what self-employment is and how it can develop for women and men. However, the "dissonance" between our perspective and the perspective of others has been a challenge; it has been a delicate task. As academics, we are trained to argue logically from a certain standpoint. However, it is important for researchers to communicate their results - not only within their own discourse but also between discourses, particularly since they can have a joint interest.

\section{References}

Acker, J. (1990), "Hierarchies, jobs, bodies: a theory of gendered organizations", Gender and Society, Vol. 4 No. 2, pp. 139-158. doi:10.1177/089124390004002002.

Ahl, H. (2006), "Why research on women entrepreneurs needs new directions", Entrepreneurship Theory and Practice, Vol. 30 No. 5, pp. 595-621. doi: 10.1111/j.1540-6520.2006.00138.x.

Berggren, C. and Olofsson, A. (2011), "From higher education studies to self-employment - a matter of discipline and gender?", paper presented at the The European Conference on Educational Research (ECER), Berlin, 13-16 September.

Bjerke, B. (2013), A Book about Entrepreneurship, Edward Elgar, Cheltenham.

Bourdieu, P. (2001), Masculine Domination, Polity Press, Cambridge.

Fleck, E., Hegarty, C. and Neergaard, H. (2011), "The politics of gendered growth”, International Journal of Gender and Entrepreneurship, Vol. 2 No. 2, pp. 164-173. doi: 10.1108/ 17566261111140224 .

From, J. (2010), “Contradictions at play”, eJournal of Education Policy JEP, available at: www4. nau.edu/cee/jep/journals.aspx?id $=321$

Greene, J.C. (2007), Mixed Methods in Social Inquiry, Jossey-Bass, San Francisco, CA.

Greene, J.C. (2012), "Engaging critical issues in social inquiry by mixing methods", American Behavioral Scientist, Vol. 56 No. 6, pp. 755-773. doi: 10.1177/0002764211433794.

Holmquist, C. (2002), "Integration mellan genus- och entreprenörskapsteori - är det möjligt och/ eller önskvärt? [Integration between gender and entrepreneurship theory - is it possible and/or desirable?]", in Holmquist, C. and Sundin, E. (Eds), Företagerskan. Om kvinnor och entreprenörskap [The Business Woman. About Women and Entrepreneurship], SNS, Stockholm, pp. 47-67.

Holmquist, C. and Sundin, E. (1990), "What's special about highly educated women entrepreneurs?”, Entrepreneurship \& Regional Development, Vol. 2 No. 2, pp. 181-194. doi: $10.1080 / 08985629000000012$. 
IJGE
7,3

302

Ridgeway, C.L. (1997), "Interaction and the conservation of gender inequality: considering employment”, American Sociological Review, Vol. 62 No. 2, pp. 218-235, available at: www. jstor.org/stable/2657301

Ridgeway, C.L. and Correll, S.J. (2004), "Unpacking the gender system. A theoretical perspective on gender beliefs and social relations", Gender \& Society, Vol. 18 No. 4, pp. 510-531, available at: www.jstor.org/stable/4149448

Schumpeter, J.A. and Schumpeter, E.B. (1994), History of Economic Analysis, Oxford University Press, New York, NY.

Shaw, E., Marlow, S., Lam, W. and Carter, S. (2009), "Gender and entrepreneurial capital: implications for firm performance", International Journal of Gender and Entrepreneurship, Vol. 1 No. 1, pp. 25-41. doi: 10.1108/17566260910942327.

Watson, J., Newby, R. and Mahuka, A. (2009), “Gender and the SME 'finance gap”, International Journal of Gender and Entrepreneurship, Vol. 1 No. 1, pp. 42-56. doi: 10.1108/17566260910942336.

West, C. and Zimmerman, D.H. (1987), "Doing gender”, Gender \& Society, Vol. 1 No. 2, pp. 125-151, available at: www.jstor.org/stable/189945

\begin{abstract}
About the authors
Caroline Berggren is Senior Lecturer at the Department of Education and Special Education at the University of Gothenburg. He is currently running a project "Gender and class perspectives on students' choice of higher education institutions and graduates' choice of job location" together with professor Anders Olofsson. Caroline Berggren is the corresponding author and can be contacted at: caroline.berggren@ped.gu.se

Anders Olofsson is Professor at Mid Sweden University. He is currently running a project "Gender and class perspectives on students' choice of higher education institutions and graduates' choice of job location" together with Senior Lecturer Caroline Berggren. Further, he is Senior Researcher in the project Social Entrepreneurship in Sparsely Populated Areas (SESPA).
\end{abstract}

For instructions on how to order reprints of this article, please visit our website:

www.emeraldgrouppublishing.com/licensing/reprints.htm

Or contact us for further details: permissions@emeraldinsight.com 